\title{
Localized Gallbladder Carcinoma
}

National Cancer Institute

\section{Source}

National Cancer Institute. Localized Gallbladder Carcinoma. NCI Thesaurus. Code C7649.

A carcinoma that arises from the gallbladder and it has not spread to other anatomic sites. 